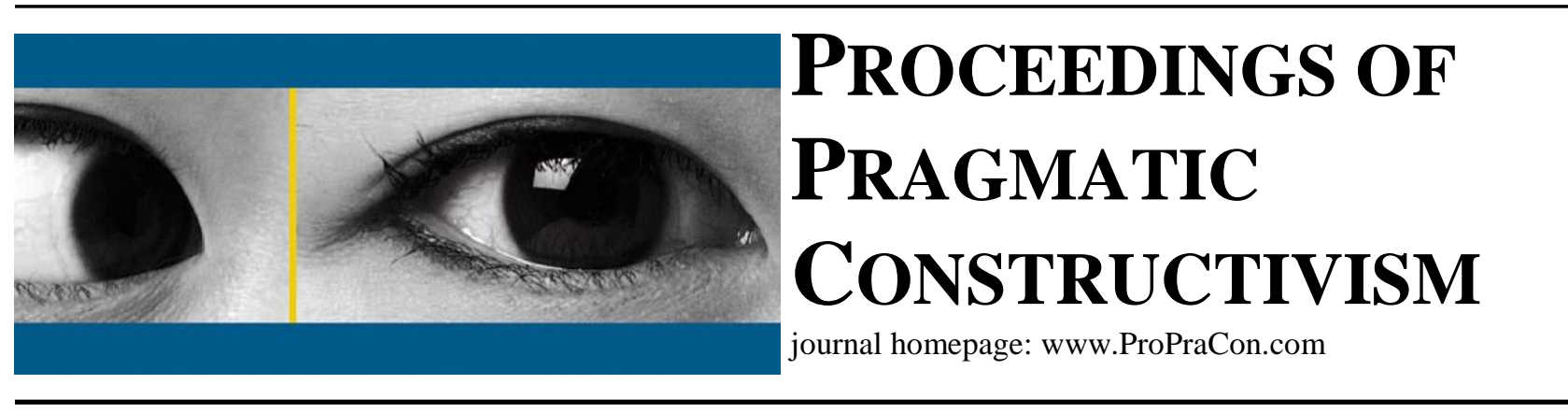

\title{
Costing vs. prediction machines in pricing decisions A Pragmatic Constructivist approach
}

\author{
Trond Bjørnenak \\ Department of Accounting, Auditing and Law, \\ NHH Norwegian School of Economics, Norway \\ Email: trond.Bjornenak@nhh.no \\ Hanne Nørreklit \\ Department of Management, \\ Arhus University, Denmark \\ E-mail: hannenorreklit@mgmt.au.dk
}

Pricing is a very complex decision making process that do not rely on any one discipline but involve many different theoretical aspects such as management accounting, economics and marketing. The economic approach to optimal pricing follows the Amoroso-Robinson rule that states that the only relevant information is the marginal cost (MC) and the price elasticity (Amoroso, 1930; Robinson, 1933). According to this, only the estimation of marginal cost is relevant for pricing decisions, which normally rules out the relevance of full cost.

However, empirical research shows that full-cost pricing is the dominant form of pricing behaviour (see e.g. Laitinen, 2011). This reality gap has been discussed in a number of different publications and approaches (see e.g. Scapens, 1994). Pricing as a process that gives coherence and meaning to organizational behaviour is one of them. Ahmed and Scapens (2000) argue that management accounting systems traditionally are not designed to estimate marginal cost, but to ensure systematic recovery of all cost and a reasonable return on investment. This is consistent with Schmalenbarch's (1919) argumentation in Selbstkostenrechnung und preispolitik (full-costing and price policy).

Today we observe another interesting deviation from the AR pricing rule. Now, it is the price elasticity rule that is questioned. Prediction machines are developed using artificial intelligence (AI), machine learning and big data (Agrawal, Gans and Goldfarb, 2018). The purpose of these prediction machines (in pricing) is to predict how demand is associated with a number of factors. The view is that we should not look at the elasticity of all customers, because the group of customers have different elasticity. One single person can have different opinions at different points of time and in different settings. Big data sets and advanced statistical methods opens up new opportunities to explore and exploit such variations.

In this paper we adopt a pragmatic constructivist approach to understand the two deviations from the AR rule of pricing. PC acknowledges that actors use costing systems to construct their relationship to factual possibilities. In fullcost pricing, facts (e.g. cost), opportunities (e.g. price changes), values (e.g. customer relations) and communications (i.e. system / actor interaction) are integrated to create sustainable profit. Demand side opportunities and price discrimination are limited. In the "new" world of Big Data, facts, opportunities, values and communication are significantly changed. Revenues are more important than costs, the value dimension is disconnected from the system, opportunities are mainly external and the system-actor interaction is at best weak.

The PC approach highlights the potential danger of prediction machines. At the society level, it may reduce the level of trust. At an organisational level, it may lead to less attention to costs and internal value creation. However, it may also be highly profitable for many companies. 